\title{
COMPARISION OF SEVERAL SECONDARY METABOLITE AND ELEMENTAL ION CONTENTS OF LEAVES FROM Kandelia obovata AND Sonneratia caseolaris FORESTS LOCATED IN THE RED RIVER DELTA
}

\author{
Nguyen Thi Ngoc Loan', Dao Van Tan ${ }^{1, *}$, Tran Thi Thanh Huyen ${ }^{1}$, Nguyen Hong Quang ${ }^{2}$, \\ Le Thi Van Hue ${ }^{3}$, Pham Thi Thanh Nga $^{2}$, Claire Quinn, ${ }^{4}$ Rachael Carrie ${ }^{4}$, \\ Lindsay C. Stringer ${ }^{4}$, Chris Hackney ${ }^{5}$ \\ ${ }^{1}$ Hanoi National University of Education, Ha Noi, Vietnam \\ ${ }^{2}$ Vietnam National Space Center, VAST, Vietnam \\ ${ }^{3}$ Central Institute for Natural Resources and Environmental Studies, VNU, Vietnam \\ ${ }^{4}$ Sustainability Research Institute, School of Earth and Environment, \\ University of Leeds, Leeds, United Kingdom \\ ${ }^{5}$ School of Geography, Politics and Sociology, Newcastle University, \\ Newcastle upon Tyne, United Kingdom
}

Received 14 May 2020, accepted 25 September 2020

\begin{abstract}
The two mangrove species Kandelia obovata and Sonneratia caseolaris were widely planted in the Red River delta. Both K. obovata and S. caseolaris forests play an important role in the economic development and environmental protection of the delta. However, chemical responses of the common mangrove forests to different ecological conditions in the delta have not yet been described. In this study, we evaluated chemical responses of $K$. obovata and $S$. caseolaris through comparisons of the content of metabolites and element ions in leaves of mangrove plants located under different ecological conditions in the Red River delta. In the low salinity area (Thuy Truong), specific leaf areas of $K$. obovata and $S$. caseolaris were much lower while the succulent index was higher compared to those in the high salinity area (Kim Trung). In Kim Trung, both species had a lower ratio of chlorophyll a/chlorophyll b. K. obvata in lower light (under the $S$. caseolaris canopy) had lower levels of chlorophyll b, resulting in a higher Chla/chlb ratio. There was no difference in the $\mathrm{Mg}$ content of leaves between two areas. An increase in $\mathrm{Na}$ content in leaves of mangrove plants in the higher salinity area was evident. The high $\mathrm{K} / \mathrm{Na}$ ratio in leaves were eveluated for both species in high salinity areas. Our results also showed better uptake of $\mathrm{K}$ in leaves of $S$. caseolaris growing in the low salinity conditions (Thuy Truong), i.e. Thuy Truong has more favourable ecological conditions for $S$. caseolaris. Carotenoid contents in leaves of both species growing in the higher salinity were lower.
\end{abstract}

Keywords: Kandelia obovata, Sonneratia caseolaris, chlorophyll, elements, pigment, salinity, total phenolic, Red River.

Citation: Nguyen Thi Ngoc Loan, Dao Van Tan, Tran Thi Thanh Huyen, Nguyen Hong Quang, Le Thi Van Hue, Pham Thi Thanh Nga, Quinn C., Carrie R., Stringer L. C., Hackney Ch., 2020. Comparision of several secondary metabolite and elemental ion contents of leaves from Kandelia obovata and Sonneratia caseolaris forests located in the Red River delta. Academia Journal of Biology, 42(4): 87-99. https://doi.org/10.15625/2615-9023/v42n4.15068

*Corresponding author email: tandv@ @nue.edu.vn

C2020 Vietnam Academy of Science and Technology (VAST) 
Nguyen Thi Ngoc Loan et al.

\section{INTRODUCTION}

The Red River delta (RRD), located in the northern Vietnam, plays a vital role in the agricultural, industrial and economic development of the country. The main branches of the Red River and several other tributaries including Duong, Thai Binh, Luoc, Tra Ly, Day rivers flow through the delta (Minh et al., 2014). The large fresh water flows from the complex hydrological network of tributaries and distributaries provide favorable conditions for developments of mangroves. As the region is affected by strong typhoons, mangroves provide valuable protection, buffering the coast from storm surges. Mangrove forests in the delta are also important in protection and economic development of local communities, as well as in carbon accumulation (Hanh, 2016; Nguyen Ha Thanh et al., 2004). Two plant species, Kandelia obovata and Sonneratia caseolaris, which dominate the natural mangrove forest have been widely planted by local people (Cuc \& Tan, 2004; Hong, et al., 2004; Hong, et al., 2003). Most mangrove plantations were planted before 2005. By 2004, the delta possessed more than 20,000 ha of mangrove forests, with $14.8 \%$ of total area being plantation (Tang, 2006).

Mangrove plants respond and adapt to environmental variations and changes in the RRD in different ways. Increasing accumulation of chemical ions in leaves has been demonstrated recently (Chen et al., 2018; Farooqui et al., 2016; Medina et al., 2015). Changes in pigments and phenolic content in plants when the environmental factors such as temperature changed were studied (Norshazila et al., 2017). In this study, we evaluated response of mangrove plants through comparison of the content of some metabolites and element ions in leaves of mangrove plants planted at sites with different ecological conditions in the RRD. Understanding the difference in chemical contents in mangrove leaves may provide helpful information for mangrove reforestation.

\section{MATERIALS AND METHODS}

\section{Study sites}

The RRD biophere reserve, including mangrove forests of the districts of Thai Thuy, Tien Hai, Giao Thuy, Nghia Hung and Kim Son, was established in 2004. The forest in the delta comprises three types of mangrove plantation: $K$. obovata, S. caseolaris and $K$. obovata mixed with $S$. caseolaris (Cuc \& Tan, 2004; Hong et al., 2003; Manh \& Doi, 2018). The area contains three large estuaries: Thai Binh; Ba Lat and Day. Approximately 116 million tons of alluvia per annum are brought downtream by the Red and Thai Binh river systems (Hong et al., 2004).

Thuy Truong and Kim Trung communes have quite similar types of mangrove plantations but they have different ecological conditions especially salinity. Therefore, Thuy Truong Commune, Thai Thuy District, Thai Binh Province and Kim Trung Commune, Kim Son District, Ninh Binh Provinces were selected as study sites.

From 1994 to 2002, mangrove forest area in Thuy Truong grew from 400 ha to 650 ha (Cuc \& Tan, 2004). The area receives fresh water flows and a huge quantity of aluvia from Thai Binh and Luoc rivers through the Thai Binh estuary. The salinatiy of the mangrove areas fluctuates from 5\% to $15 \%$ (field data in January (2018) and August (2018), measured with hand-held refractometer ATGO S-28 (Japan). K. obovata and $S$. caseolaris are the dominant species in Thuy Truong. The S. caseolaris forests here have different ages, with some estimated to be 50 years old while others were mostly planted from 2013. K. obovata forests in Thuy Truong were planted from 1986 but most were cut down and replanted between 1999 and 2008. It was estimated in 2015 that there were approximately 780 ha of mangrove forest in Thuy Truong (Manh \& Doi, 2018). In this study, a 6 year-old $S$. caseolaris forest (SC_TT2) and an approximately 13 year-old K. obovata forest (KO_TT1) in Thuy Truong were selected for sampling (Fig. 1). The soil in the 13 year-old $K$. obovata forest is quite 
firm sediment and contains abundant alluvia. The soil in 6 year-old $S$. caseolaris forest is a mixture of sand and alluvia.

Kim Trung is one of three communes with mangroves in Kim Son District. According to images of Landsat and SPOT, the current mangrove forests were detected from the years of 2000s (Nguyen et al., 2019). The mangrove forest in Kim Trung is located aproximately $7 \mathrm{~km}$ from the Day estuary. The salinity of mangrove areas fluctuates between 9-24\%o (field data), depending on the season. The sea dyke Binh Minh 3 splits the Kim Trung mangroves into areas outside and inside the dyke. A recent study revealed that $K$. obovata forests in Kim Dong, a nearby commune, were planted seaward from the sea dyke in 2008, 2009 and 2010 (Hanh, 2016; Minh ate al., 2015). In Kim Trung, a 9 yearold $K$. obovata forest (KO_KT3) and a 4 yearold S.caseolaris mixed with $K$. obovata forest (SC_KT4) were selected for sampling (Fig. 1). The K. obovata was under the canopies of $S$. caseolaris in the mixed forest. Both mangrove forests were located outside the sea dyke. The soil in $K$. obovata forest are soft mud while the soil in the mixed forest is firm and sandy.

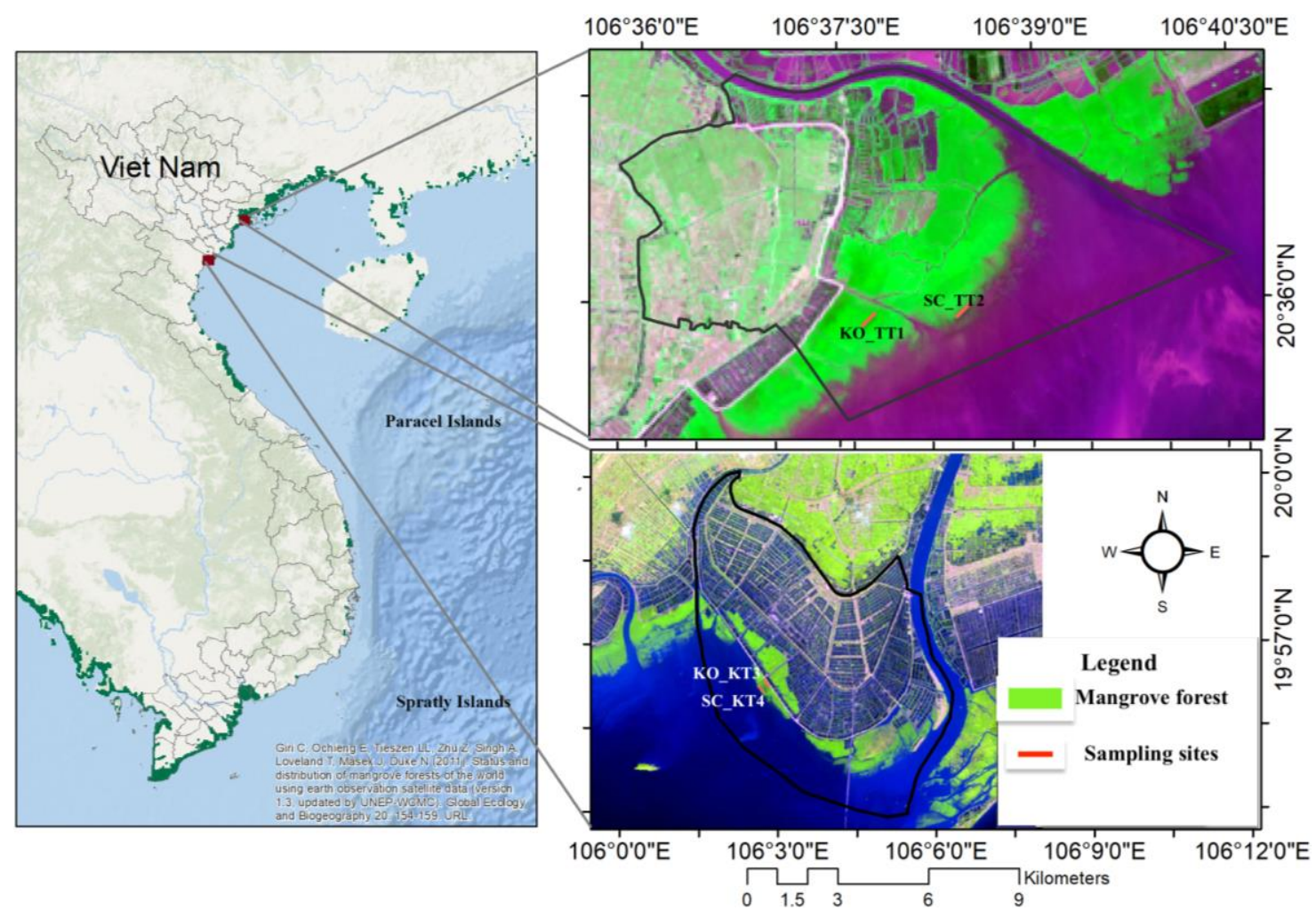

Figure 1. Study sites based on Lanset images (2018). The red lines represent sites of sample collection

\section{Sample preparation}

Leaf samples were collected in August 2019. For determination of pigment content, 6 $\mathrm{cm}^{2}$ of mature leaves were preserved in $90 \%$ acetone in the darkness at $4{ }^{\circ} \mathrm{C}$. For each mangrove forest, 27 samples were collected.
The samples for determination of phenolic and element contents were preserved in the darkness at $4{ }^{\circ} \mathrm{C}$. The samples then were dried at $105{ }^{\circ} \mathrm{C}$ for $30 \mathrm{~min}$ and then dried at $60{ }^{\circ} \mathrm{C}$ for 72 hours until a constant weight was reached. The dried samples were ground into powder and stored at minus $20{ }^{\circ} \mathrm{C}$ until use. 


\section{Determination of pigment content}

Pigment was extracted with $5 \mathrm{ml}$ of $90 \%$ acetone, in triplicate. After filtering, the filtrate of three extractions were mixed to measure light absortion at $647 \mathrm{~nm}, 664 \mathrm{~nm}$, and $470 \mathrm{~nm}$ using a photospectometer (Biotex Epoch 2, USA). Chlorophyll (Chl) content was calculated as documented by Jeffer \& Humphrey (1975) and the carotenoid content was calculated as outlined by Wellburn (1994):

$$
\begin{gathered}
\text { Chla }(\mu \mathrm{g} / \mathrm{mL})=11.93 \times \mathrm{A}_{664}-1.93 \times 647 \\
\operatorname{Chlb}(\mu \mathrm{g} / \mathrm{mL})=20.36 \times \mathrm{A}_{647}-5.5 \times \mathrm{A}_{664} \\
\operatorname{Car}(\mu \mathrm{g} / \mathrm{mL})=\left(1000 \times \mathrm{A}_{470}-1.82 \times \text { Chla }-\right. \\
85.02 \times \text { Chlb }) / 198
\end{gathered}
$$

Where: Chla; Chlb: Chlorophyll a and chlorophyll b content, respectively; Car: carotenoid content; $\mathrm{A}_{664}, \mathrm{~A}_{647}, \mathrm{~A}_{470}$ : absorbtion at $664 \mathrm{~nm}, 647 \mathrm{~nm}$ and $470 \mathrm{~nm}$.

\section{Determination of total phenolic content}

Phenolics were extracted according to Kim \& Lee (2002). $100 \mathrm{mg}$ of sample powder was soaked with $1.0 \mathrm{ml}$ of $80 \%$ methanol, then extracted by ultrasonic vibration for 20 minutes. The mixture was filtered through Whatman No2 paper by vacuum suction using a Buchner funnel. The residue was reextracted one more time. Two filtrates were mixed for further analysis. The mixed filtrate then was used for measuring total phenolic content using Folin-Ciocalteau reagent according to a modified method of Kim \& Lee (2002) using gallic acid to build standard curves. Absorbtion at $750 \mathrm{~nm}$ was measured by photospectometer (Biotex Epoch 2, American). For each species from each forest, 8-10 leaf samples were used for analysis.

\section{Determination of chemical element content}

Sample powder $(500 \mathrm{mg})$ was ashed with a muffle furnace (Jakovljević et al., 2003) at 350 ${ }^{\circ} \mathrm{C}$ for 30 minutes. Temperatures were then increased to $550{ }^{\circ} \mathrm{C}$ for 3 hours. The ashed samples then were dissolved in $5 \mathrm{ml}$ of $\mathrm{HCl}$ for 15 minutes. Deionised water was added until samples reached $50 \mathrm{ml}$ and then filtered. $\mathrm{Ca}^{2+}$ and $\mathrm{Mg}^{2+}$ contents were determined by atomic absorption spectrometry (AAS) using the standard at concentrations of $12.5 \mathrm{mg} / \mathrm{L}$ to 100 $\mathrm{mg} / \mathrm{L}$. The content of $\mathrm{K}$ and $\mathrm{Na}$ contents were determined by a flame-photometric method using standard concentration of $6.25 \mathrm{mg} / \mathrm{L}$ to $50 \mathrm{mg} / \mathrm{L}$. For each species per each forest, 8-10 leaf samples were analysed.

\section{Calculation of relative water content, specific leaf area and succulence}

Relative water content, specific leaf area and succulence (SLA) were calculated following Medina et al. (2015). Relative water content was expressed as the percentage of water in the leaves ([fresh mass-dry mass] $x$ $100 /$ Fresh mass). Specific leaf area index was calculated as the ratio of area/dry mass and expressed as $\mathrm{m}^{2} \mathrm{~kg}^{-1}$ leaves. The succulence index was calculated as the water content per unit area expressed as $\mathrm{kg}$ water $\mathrm{m}^{-2}$ ([fresh mass-dry mass]/area).

\section{Data processing}

Data were processed and analysed using ANOVA at $p=0.05$, SPSS 20 . The data were represented as mean \pm standard deviation (SD).

\section{RESULTS}

Water content, specific leaf area and succulence of leaves

Relative water content of $K$. obovata leaves in Thuy Truong was significantly lower than that of $S$. caseolaris leaves and $K$. obovata leaves in Kim Trung (Fig. 2). In the same forest, there was also a difference in relative water content between two species. No differences in relative water content was detected between leaves of $S$. caseolaris at different study sites.

The specific leaf area (SLA) of K. obovata in Thuy Truong was much lower than the leaves of the same species in Kim Trung. A difference in the $S$. caseolaris SLA between Thuy Truong and Kim Trung was observed (Fig. 2). There were no differences in SLA of $K$. obovata leaves collected from different forests but there was a difference in this index between two species in Kim Trung. The succulence of $S$. caseolaris leaves in Kim Trung was lower than the others. 


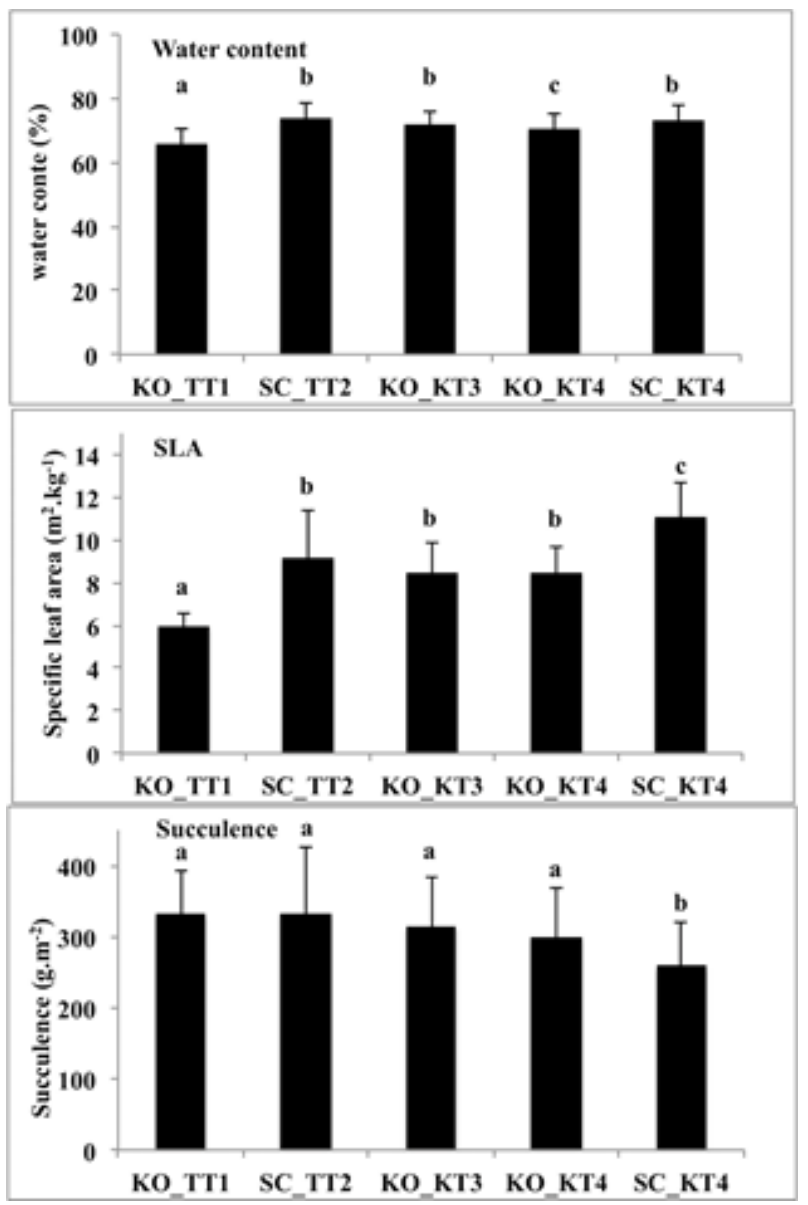

Figure 2. Water content, specific leaf area (SLA) and succulence of leaves of $K$. obovata collected from Thuy Truong $K$. obovata forest (KO-TT1), Kim Trung K. obovata forest (KO_KT3), Kim Trung mixed forest (KO_KT4) and leaves of $S$. caseolaris collected from Thuy Truong S. caseolaris forest (SC_TT2) and Kim Trung mixed forest (SC_KT4). The different letters show the significant difference $(\mathrm{P}=0.05$, Tukey test for water content and Dunett $\mathrm{T} 3$ for dry mass per area). At least 40 leaves for each species in each mangrove forest type were measured

\section{Pigment content}

There were diffenences in total chlorophyll content of $K$. obovata in the mixed forest in Kim Trung compared to the same species in other forests and different species in the same forest. In the mixed forest, $S$. caseolaris had a large canopy higher than that of $K$. obovata. Although there were no differences in total chlorophyll content between $S$. caseolaris leaves collected from different sites, there were differences in both chlorophyll a and chlorophyll b contents, as well as in the ratio of chlorophyll a/chlorophyll b (Fig. 3). Although there was no difference in total chlorophyll content of $K$. obovata leaves collected from $K$. obovata forests located in different sites, there was a difference in chlorophyll $b$ content, therefore leading to a difference in the ratio of chlorophyll a/chlorophyll b. Interestingly, the leaf of $K$. obovata, which grows on soft muddy soil and high salinity (KO_KT3) contained higher content of chlorophyll $\mathrm{b}$ in comparision to the species growing on low salinity and firm soil (Thuy Truong). 


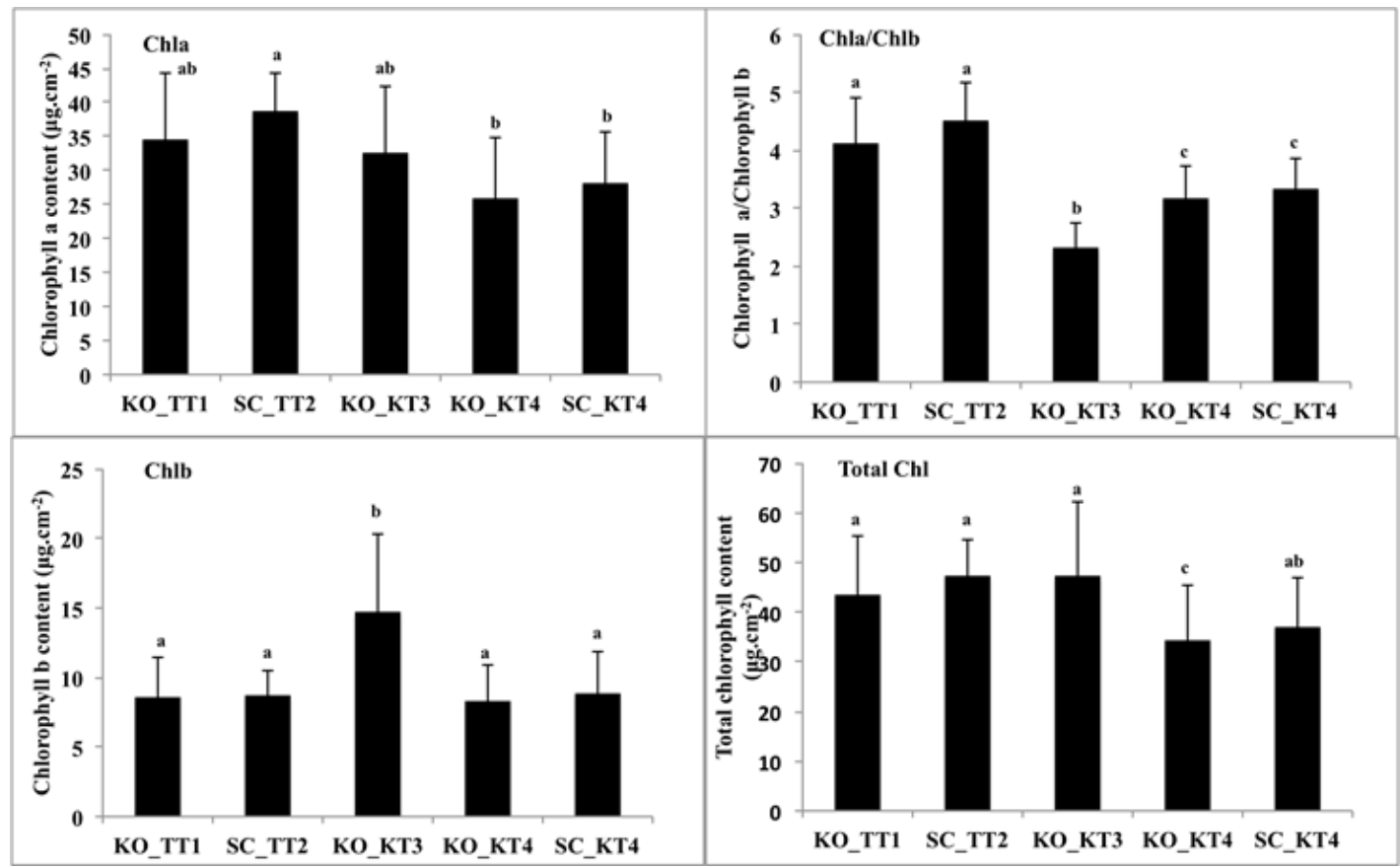

Figure 3. Chlorophylla, Chlorophyll b (Chlb) and total chlorophyll (total Chl) contents and chlorophyll a and b ratios (Chla/Chlb) of leaves of $K$. obovata collected from Thuy Truong $K$. obovata forest (KO-TT1), Kim Trung K. obovata forest (KO_KT3), Kim Trung mixed forest

(KO_KT4) and leaves of $S$. caseolaris collected from Thuy Truong S. caseolaris forest (SC_TT2) and Kim Trung mixed forest (SC_KT4). The different letters show the significant difference $(\mathrm{P}=0.05$, Dunett $\mathrm{T} 3$ test $)$

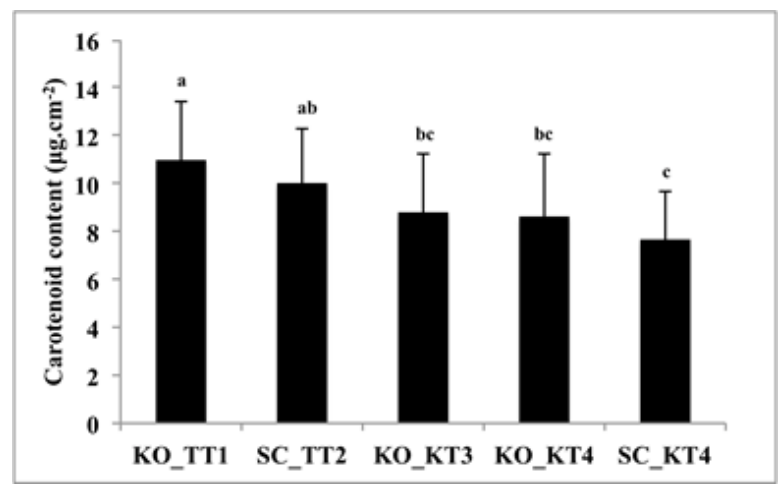

Figure 4. Carotenoid content of leaves of K.obovata collected from Thuy Truong K. obovata forest (KO-TT1), Kim Trung K. obovata forest (KO_KT3), Kim Trung mixed forest (KO_KT4) and leaves of $S$. caseolaris collected from Thuy Truong $S$. caseolaris forest (SC_TT2) and Kim Trung mixed forest (SC_KT4). Olumm share the same letters show no significant difference $(\mathrm{P}=0.05$, Tukey test $)$

Carotenoid contents in leaves collected from different mangrove forests are shown in Fig. 4. Both $K$. obovata and $S$. caseolaris planted in Thuy Truong (lower salinity) had higher leaf carotenoid content compared to those in Kim Trung. There were no clear differences in carotenoid content of the two species located at same sites or in the same forest. 


\section{Total phenolic content}

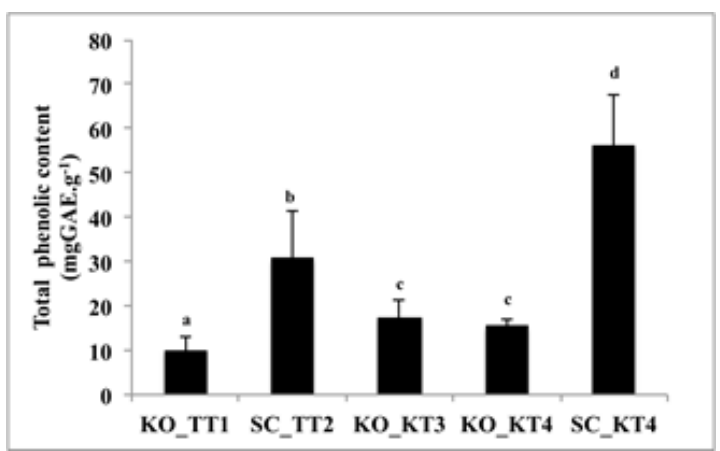

Figure 5. Total phenolic content of leaves of $K$. obovata collected from Thuy Truong $K$. obovata forest (KO-TT1), Kim Trung $K$. obovata forest (KO_KT3), Kim Trung mixed forest (KO_KT4) and leaves of S. caseolaris collected from Thuy Truong S. caseolaris forest (SC_TT2) and Kim Trung mixed forest (SC_KT4). The different letters show the significant difference $(P=0.05$, Dunnet's T3 test)

The two species displayed different total phenolic contents even they grew in the same area. S. caseolaris had higher total phenolic content (Figure 5). The same species planted in different areas had different total leaf phenolic contents.

\section{Chemical element content}

Only two differences in $\mathrm{Ca}$ content of the mangrove leaves were observed: between $S$. caseolaris from the two areas and between $S$. caseolaris and $K$. obovata planted in different forests in Kim Trung (Fig. 6). There were no differences in $\mathrm{Mg}$ content of mangrove leaves collected from different sites. K content in $S$. caseolaris planted in Thuy Truong was higher than in the same species planted in Kim Trung and in K. obovata planted in Thuy Truong. K content in the $K$. obovata leaves was stable under the different conditions. In contrast, $\mathrm{Na}$ content of mangrove leaves differed between Thuy Truong and Kim Trung. The molar ratio of $\mathrm{K} / \mathrm{Na}$ in $S$. caseolaris is higher than in $K$. obovata (Fig. 7). Regarding S. caseolaris, this ratio was higher in Thuy Truong, where salinity is greater, compared to Kim Trung.

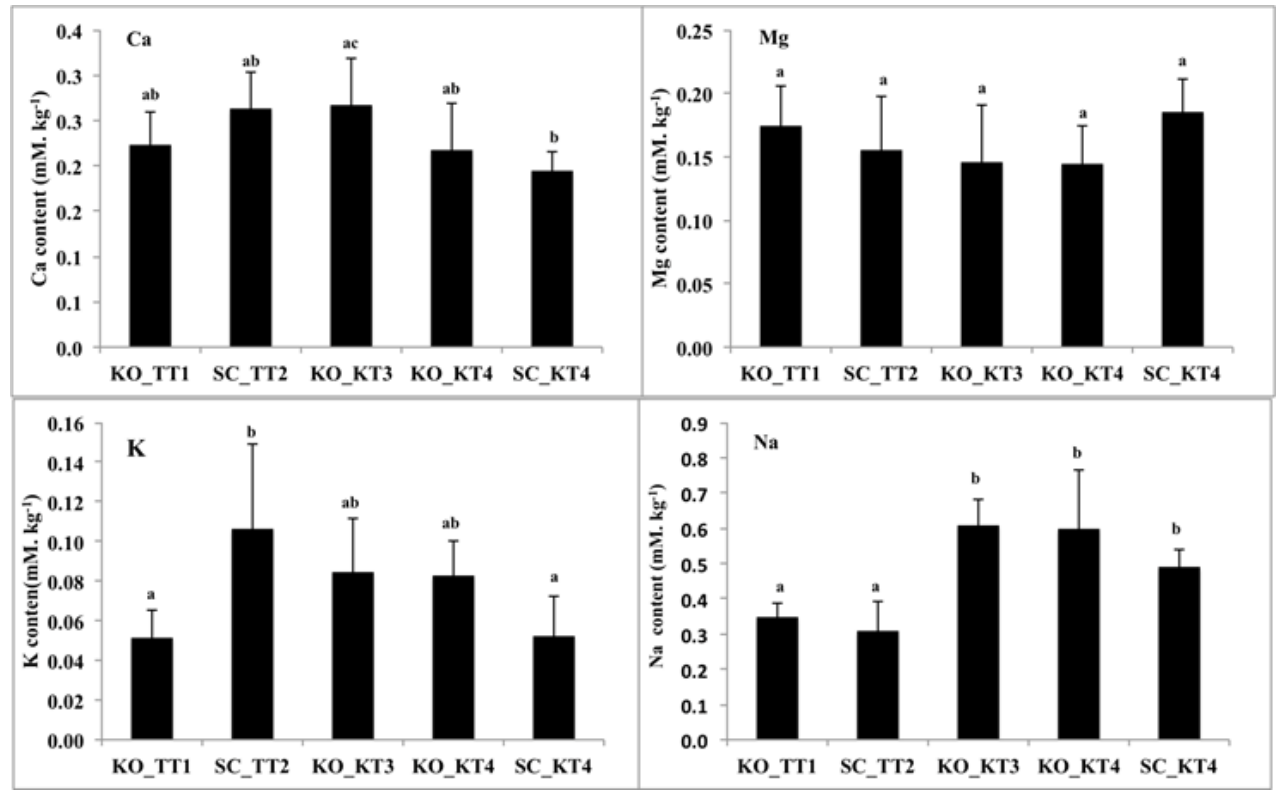

Figure 6. Element content of leaves of K.obovata collected from Thuy Truong K. obovata forest

(KO-TT1), Kim Trung K. obovata forest (KO_KT3), Kim Trung mixed forest (KO_KT4) and leaves of $S$. caseolaris collected from Thuy Truong $S$. caseolaris forest (SC_TT2) and Kim Trung mixed forest (SC_KT4). The different letters show the significant difference $(\mathrm{P}=0.05$, Tukey test) 


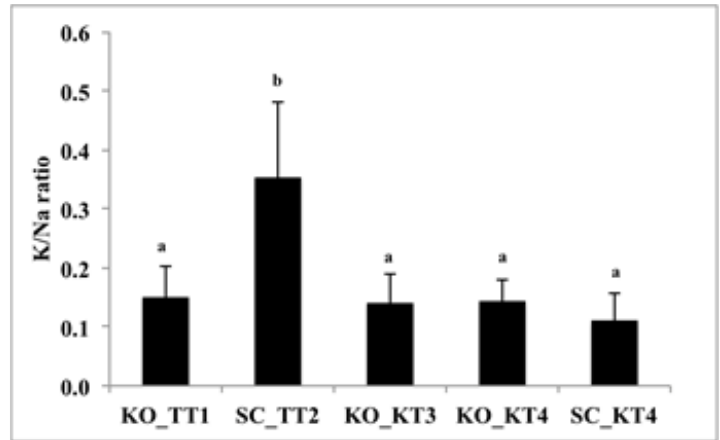

Figure 7. K/Na ratio in leaves of $K$. obovata collected from Thuy Truong $K$. obovata forest

(KO-TT1), Kim Trung K. obovata forest

(KO_KT3), Kim Trung mixed forest

(KO_KT4) and leaves of S. caseolaris collected from Thuy Truong $S$. caseolaris forest (SC_TT2) and Kim Trung mixed forest

(SC_KT4). The different letters show the significant difference $(\mathrm{P}=0.05$, Tukey test)

\section{DISCUSSION}

Mangroves can be distinguished into 2 categories: salt-excluding and salt-secreting mangroves (Scholander et al., 1962). Two genera Kandelia and Sonneratia are saltexcluding mangroves. The leaves of true mangrove plant possess xeromophic features such as water storage tissue. K. obovata and $S$. caseolaris were thought to possess mesophyll acting as water storage tissue throughout a leaf's life (Chapman, 1975). However recent reports revealed that the process of water storage took place in during senescence (Dang et al., 2004, Medina et al., 2015). Relative water content was reported to be reduced in June under short-term salt stress (Chaudhuri \& Choudhuri, 1997). Medina et al. (2015) indicated that $L$. racemosa developed a high degree of succulence, particularly during the transition from mature to senescent leaves.

In our study, succulence as well as the relative water content of matured $S$. caseolaris leaves were not greater in the higher salinity area (Kim Trung) supporting the development of succulence at high degree during the transition of mature to senescent leaves (Medina et al., 2015). However, in this study, the $K$. obovata forest had high density and older plants. This could explain the lower relative water content and lower SLA of $K$. obovata leaves collected from Thuy Truong $K$. obovata forest.

Based on the continous decrease in SLA from young to old leaves, Medina et al. (2015) evaluated the predominance of leaf age in $L$. racemosa canopy. Their study also showed that in $R$. mangle, SLA increased from young to old leaf age categories, showing a strong increase in the senescent category (Medina et al., 2015). In our study, the lower SLA of $K$. obovata suggests the higher continuous accumulation of matter in mature leaves. The difference in SLA of $S$. caseolaris between different study areas suggests that SLA acts an indicator for the response of this species to the salanity change.

Different stressful environments such as salt, temperature and drought stresses have been reported to reduce the contents of photosynthetic pigments (Ashraf \& Harris, 2013). Salinity significantly reduced chlorophyll a, chlorophyll $\mathrm{b}$ and carotenoid contents in crops such as broad bean (Amira \& Qados, 2010). The variation in the $\mathrm{Chla} / \mathrm{Chlb}$ ratio is suggestive of adaptive changes (Das et al., 2002). The ratio is an index that reflects the shade or sun habitat of the plants and the $\mathrm{CO}_{2}$ fixation rate (Lichtenthaler et al., 2007). Species in the family Rhizophoraceae show high ratios (3.2 to 3.4) (Das et al., 2002). In rice, under salt stress conditions, the content of chlorophyll $b$ was more affected (Amirjani, 2011; Chandramohanan et al., 2014).

Our study results reveal that different species had different responses to salinity. $K$. obovata had quite stable chlorophyll b content at different salinities whereas $S$. caseolaris had clear reduction in chlorophyll $b$ in high salinity. However, both species had lower Chla/Chlb ratios under higher salinity (Kim Trung), in agreement with Das et al. (2002). As $K$. obovata forest in Kim Trung was grown in soft muddy soil, an experiment on the effects of softness of substrate on chlorophyll content in leaves should be conducted in further research. In addition, under the 
canopies of $S$. caseolaris in the mixed forest, $K$. obovata leaves contained lower total chlorophyll content (Fig. 3) and the change in chlorophyll b content was more pronounced. Chlorophyll contents of mangrove leaves in our study $(2.0-3.3 \mathrm{mg} / \mathrm{g} \mathrm{DM})$ are higher than those of a previous study (Das et al., 2002) supporting the view that photosynthetic pigment changes under different conditions.

Carotenoids are multifunctional compounds serving as structural components of light-harvesting complexes, accessory pigments for light harvesting, substrates for phytohormone synthesis, components of photoprotection and scavengers of singlet oxygen. They also play an important role under conditions of excess light (Frank \& Cogdell, 1993; McEiroy \& Kopsell, 2011; Penna 1999). Strzaka et al. (2003) reported that carotenoids fluidize the membrane in its gel state and make it more rigid in its liquid crystalline state, which results in broadening the phase transition. A significant reduction was observed in lutein content of pumpkin leaves when exposed to ultra violet light (Norshazila et al., 2017). A recent study reported that the protoplast cultures of yellow A. alba callus, which contained carotenoids, were halophilic to $\mathrm{NaCl}, \mathrm{KCl}$, and $\mathrm{MgCl}_{2}$ but not to $\mathrm{CaCl}_{2}$ (Sasamoto et al., 2020). Banerjee (2017) revealed that in mangrove plants exposed to salinity, carotenoids were significantly reduced. Our study is consistent with this report, as lower carotenoid contents of both $K$. obovata and S. caseolaris in the higher salinity area were observed. In contrast, no differences in carotenoid contents of $K$. obovata leaves under different light intensities were observed.

Phenolic compounds offer protection from predators and from ultra violet radiation, and are affected by stress (Chalker-Scott \& Fuchigami, 1989). The phenolic contents of mangrove species have been reported to be high and differed among species (Banerjee et al., 2017). Phenolic compounds from Sonneratia collected from the RRD have been fractionated and their bioactivities evaluated in previous research (Mai \& Tan, 2017; Tan
\& Thuy, 2015). Rezazadeh (2012) showed that the total phenolic accumulation of Cynara scolymus leaves increased when grown in 1.3 and $6.45 \mathrm{dSm}^{-1}$, but declined in high salinities. Reports on changes in phenolic content of mangroves with the environment are found in the literature. For example, the total phenolic content of $K$. obovata was higher in regions with more abundant sunlight and longer sunshine duration (Wang et al., 2019). However, there are limited reports on phenolic production in mangrove plants at different salinities. Our study result (Fig. 5) reveals that the total phenolic contents differed between mangrove species. Under higher salinity, both species increased accumulation of phenolic compounds in their leaves, which is consistent with the previous report (Rezazadeh et al., 2012), but accumulation was still taking place when the salinity reached $20 \mathrm{ppt}$.

The limitation of the concentration of $\mathrm{K}^{+}$ and $\mathrm{Na}^{+}$in the leaves of cultivars at high salinity levels has been reported (Ashraf \& Harris, 2013, Ulfat et al., 2007). Ca, K, Mg and $\mathrm{Na}$ contents of mangrove leaves has been investigated before (Chen, Juan, et al., 2013, Madi, et al., 2016, Medina et al., 2015). Different leaf element concentrations have been ranked among mangrove species ( $\mathrm{K}>$ $\mathrm{Mg}>\mathrm{Ca}$ in A. shaueriana; $\mathrm{Ca}>\mathrm{K}>\mathrm{Mg}$ in $L$. racemosa and $R$. mangle) (Madi et al., 2016). In our study, however, the ion content was ranked in increasing order of $\mathrm{Ca}, \mathrm{Mg}$ and $\mathrm{K}$, which is in agreement with (Medina et al., 2015). Patel \& Pandey (2009) revealed that the contents of $\mathrm{K}, \mathrm{Ca}$, and $\mathrm{Mg}$ in the mangrove plant, Aegiceras corniculatum decreased with salinity. Magnesium $(\mathrm{Mg})$ has a dominant role in photosynthesis and associated processes in the chloroplast, where up to $35 \%$ of leaf $\mathrm{Mg}$ is located. $\mathrm{Mg}$ also affects plant shoot and root formation, and cellular stress defense mechanisms in various crops and plant species (Hauer-Jákli \& Tränkner, 2019). Conditions with dry soil and high levels of competing elements, such as potassium and calcium, also result in $\mathrm{Mg}$ deficiency and a critical leaf $\mathrm{Mg}$ range for dry 
weight was found to be between 0.1 and $0.2 \%$ in many crops (Guo et al., 2015). Mg may play an important role under salt stress (Karpiuk et al., 2016). However, no differences were observed in our study, suggesting stablity of the element in the mangrove leaves.

Different efficiencies in taking up both $\mathrm{K}$ and $\mathrm{Mg}$ but similar resorption of these ions have been reported among mangrove species (Medina et al., 2015). In our study, higher K content in $S$. caseolaris planted in the lower salinity area (Thuy Truong) suggests that $S$. caseolaris is more efficient in taking up $\mathrm{K}$ in less saline conditions.

$\mathrm{Na}$ is very important for enzyme activation, photosynthesis, water use efficiency, starch formation and protein synthesis (Karpiuk et al., 2016). However, the increase in cytosol $\mathrm{Na}$ content in salt stress can cause severe ion toxicity. Plants' responses to specific toxic ions differ and depend on the type of species (Dogan et al., 2010). The higher Na content in the leaves of both $K$. obovata and $S$. caseolaris in higher salinities reveals that the affinity for $\mathrm{Na}$ absorption in the shoot system changes under different salinities.

Intracellular $\mathrm{K} / \mathrm{Na}$ balance plays vital roles in maintaining the normal physiology of living cells, particularly in processes such as the optimization of enzyme activities, and maintaining the ideal osmoticum and membrane potential for cell volume regulation and normal plant growth (Chen et al., 2013). However, high salinity conditions disturb the intracellular $\mathrm{K} / \mathrm{Na}$ balance and cause ion toxicity and osmotic stress in plants (Chen et al., 2013). Lately, the relationship between salinity tolerance and $\mathrm{K} / \mathrm{Na}$ ratio in some mangrove species has been reported (Chen et al., 2013; Farooqui et al., 2016; Medina et al., 2015; Wang L. et al., 2011). Wang Z. et al. (2011) reported that true mangroves had significantly lower $\mathrm{K} / \mathrm{Na}$ molar ratios than mangrove associates and among true mangroves, $S$. hydrophyllacea had the lowest $\mathrm{K} / \mathrm{Na}$ ratio $(0.07)$. The $\mathrm{K} / \mathrm{Na}$ of leaves of Avicennia species grown in Krishna Godavari delta, east coast of India was 0.1 to 0.6 (Farooqui et al., 2016). Higher $\mathrm{K} / \mathrm{Na}$ ratios (1.7) in A. cornitulatum in low salinities has been reported by Patel \& Pandey (2009). Chen J. et al (2013) indicated that K. obovata roots had the maximum ratio (ca 0.8 ) when grown in $100 \mathrm{mM} \mathrm{NaCl}$ due to increasing absorption of K. The low K/Na ratio (Fig. 6) of mangroves under the higher salinity condition is in agreement with previous reports. However, the high $\mathrm{K} / \mathrm{Na}$ ratio of $S$. caseolaris in the lower salinity (Thuy Truong) reveals that this species behave similarly to mangrove associates when grown in the brackish water (Wang et al., 2011).

\section{CONCLUSION}

In high salinity condition, both $S$. caseolaris and $K$. obovata exhibited a reduction in Chla/Chlb ratio but in different ways. Both $K$. obovata and S. caseolaris tend to reduce chlorphyll a content in leaves while only $K$. obovata exhibited an increase in chlorophyll b when grown in higher salinity. $K$. obovata showed a reduction in total chlorophyll and an increase in Chla/Chlb ratio when exposed to low light. Both species showed a reduction in leaf carotenoid content in high salinity. Our study results reveal the increase in total phenolic content when $K$. obovata and $S$. caseolaris are grown in high salinity. The study results also showed that changes in $\mathrm{Na}$ content in the leaves of both species are more sensitive than other elements and suggest that the uptake of $\mathrm{K}$ in $S$. caseolaris leaves is more favorable under low salinity conditions.

Acknowledgements: We would like to thank the project "Harnessing multiple benefits from resilient mangrove systems" NE/P01450X/1 for the financial support for our experiments.

\section{REFFERENCES}

Ahmed A., Ohlson M., Hoque S., Moula M. G., 2010. Chemical composition of leaves of a mangrove tree (Sonneratia apetala Buch.-Ham.) and their correlation with some soil variables. Bangladesh Journal of Botany. 39(1): 61-69. 
Amira M. S., Qados A., 2010. Effect of salt stress on plant growth and metabolism of bean plant Vicia faba (L.). Journal of the Saudi Society of Agricultural Sciences, 10(1): 7-15.

Amirjani M. R., 2011. Effect of salinity stress oon growth, sugar content, pigments and enzyme activity of rice. International Journal of Botany, 7(1): 73-81.

Ashraf M., Harris P. J. C., 2013. Photosynthesis under stressful environments: An overview. Photosynthetica, 51(2): 163-190.

Banerjee K., C howdhury G. R., Mitra A., 2017. Astaxanthin Level of Dominant Mangrove Floral Species in Indian Sundarbans. MOJ Bioorganic \& Organic Chemistry, 1(2): 1-5.

Chalker-Scott L., Fuchigami L. H., 1989. The Role of phenolic compounds in plant stress responses. In: Li, P. H., ed. Low temperature stress physiiology in crops. CRC Press, pp. 67-79.

Chandramohanan K. T., Radhakrishnan V. V., Joseph E. A., Mohanan K. V., 2014. A study on the effect of salinity stress on the chlorophyll content of certain rice cultivars of Kerala state of India. Agriculture, Forestry and Fisheries, 3(2): 67-70.

Chapman J. V., 1975. Mangrove vegetation. J. Cramer, Germany, pp. 446.

Chaudhuri K., Choudhuri M. A., 1997. Effects of short- term $\mathrm{NaCl}$ stress on water relations and gas exchange of two jute species. Biologia Plantarum, 40(3): 373-380.

Chen J., Xiong D.-Y., Wang W.-H., Hu W.-J., Simon M., Xiao Q., Chen J., Liu T.-W., Liu X., Zheng H.-L., 2013. Nitric Oxide Mediates Root $\mathrm{K}^{+} / \mathrm{Na}^{+}$Balance in a Mangrove Plant, Kandelia obovata, by Enhancing the Expression of AKT1-Type $\mathrm{K}^{+}$Channel and $\mathrm{Na}^{+} / \mathrm{H}^{+}$Antiporter under High Salinity. Plos one, 8(8): 1-11.

Chen M., Yang Z., Liu J., Zhu T., Wei X., Fan H., Wang B., 2018. Adaptation Mechanism of Salt Excluders under Saline
Conditions and Its Applications. International Journal of Molecular Sciences, 19(3668): 1-13.

Cuc N. T. K., Tan D. V., 2004. Study on Flora in the Mangrove area of Thuy Truong Commune, Thai Thuy District, Thai Binh Province In: Hong, P. N., ed. Mangrove Ecosystem in the Red River Coastal Zone. Agriculture publishing House Ha Noi, pp. 57-74.

Dang H. C., Hong P. N., Ba T. V., 2004. Study in the effects of ecological factors on the growth of Sonneratia caseolaris (L.) Engler in the nursery. In: Hong, P. N., ed. Mangrove ecosystem in the Red River coastal zone: Biodiversity, Ecology, Socio-economics, Management and Education. A. gricultural Publishing House, Ha Noi, pp. 235-252.

Das A., Parida A., Basak U., Das P., 2002. Studies on pigments, proteins and photosynthetic rates in some mangroves and mangrove associates from Bhitarkanika, Orissa. Marine Biology, 141: 415-422.

Dogan M., Tipirdamaz R., Demir Y., 2010. Salt resistance of tomato species grown in sand culture. Plant, Soil and Environment, 56: 499-507.

Farooqui A., Joshi Y., 2016. Low Na/K ratio in the leaves of mangroves mitigates salinity stress in estuarine ecosystem. Tropical Plant Research, 3(1): 78-86.

Frank H., Cogdell R. J., 1993. Photochemistry and Func-tion of Carotenoids in Photosynthesis. In: Young, A., Britton, G., eds. Carotenoids in Photosynthesis. Chapman and Hall, London, pp. 253-315.

Guo W., Chen S., Hussain N., Cong Y., Liang Z., Chen K., 2015. Magnesium stress signaling in plant: Just a beginning. Plant signaling \& Behavior, 10(3): e9922871-e9922875.

Hanh N. T. H., 2016. Assessment of the ability of mangroves to serve as accumulated carbon sinks in the plantations in Kim Dong commune, Kim 
Son district, Ninh bBnh province, Vietnam. Academia Journal of Biology, 38(4): 521-527.

Hauer-Jákli M., Tränkner M., 2019. Critical Leaf Magnesium Thresholds and the Impact of Magnesium on Plant Growth and Photo-Oxidative Defense: A Systematic Review and Meta-Analysis From 70 Years of Research. Frontiers in Physiology, 10: 1-15.

Hong P. N., Hien V. T., Tho N. H., Thuy T. V., 2004. Some natural features of the mud flats in the coatal estuarine mangrove area of Thai Binh and Nam Dinh Provines. In: Hong, P. N., ed. Mangrove Ecosystem in the Red River Coastal Zone. Agricultural Publishing House, Ha Noi, pp. 1-15.

Hong P. N., Tan D. V., Hien V. T. \& Tran Van Thuy, 2003. Characterics of mangrove vegetation in Giao Thuy District. In: Hong, P. N., ed. Mangrove ecosystem in the Red River coastal zone: Biodiversity, Ecology, Socio-economics, Management and Education. Agricultural Publishing House, Ha Noi, pp. 75-91.

Jakovljević M. D., Kostić N. M., AntićMladenović S. B., 2003. The availability of base elementsisepi( $\mathrm{Ca}, \mathrm{Mg}, \mathrm{Na}, \mathrm{K})$ in some important soil types in Serbia. Proceedings for Natural Sciences, 104: 11-21.

Jeffrey S. W., Humphrey G. F., 1975. New spectrophotometric equations for determining chlorophylls a, b, c1 and c2 in higher plants, algae and natural phytoplankton. Biochemie und Physiologie der Pflanzen, 167(2): 191-194.

Karpiuk U. V., Azzam K. M. A., Abudayeh Z. H. M., Kislichenko V., Naddaf A., Cholak R., Yemelianova O., 2016. Qualitative and Quantitative Content Determination of Macro-Minor Elements in Bryonia Alba L. Roots using Flame Atomic Absorption Spectroscopy Technique. Advanced Pharmaceutical Bulletin, 6(2): 285-291.

Kim D. O., Lee C. Y., 2002. Extraction and isolation of polyphenolics. Current
Protocol in Food Analytical Chemistry, Vol. 6. Wiley, pp. I1.2.1-I1.2.12.

Lichtenthaler H. K, Ac A., Merk M. V, Kalina J., Urban O., 2007. Differences in pigment composition, photosynthetic rates and chlorophyll fluorescence images of sun and shade leaves of four tree species. Plant Physiol. Biochem, 45(8): 577-588.

Madi A. P. L. M., Boeger M. R. T., Reissmann C. B., Martins K. G., 2016. Soil-plant nutrient interactions in two mangrove areas at Southern Brazil. Acta Biológica Colombiana, 21(1): 39-50.

Mai N. S., Tan D. V., 2017. Fractionation of phenolic compounds from Sonneratia apetala pneumatophores and their bioactivities. Academia Journal of Biology, 39(4): 451-456.

Manh D. Q., Doi B. T., 2018. Site classification and assessment on growth and qulity of planted mangrove forest in coastal Thai Binh Province. Forest Science and Technology Journal. 153-159 (in Vietnamese).

McEiroy J. S., Kopsell D. A., 2011. Physiological role of carotenoids and other antioxidants in plants and application to turfgrass stress management. New Zealand Journal of Crop and Horticultural Science, 37(4): 327-333.

Medina E., Fernandez W., Barboza F., 2015. Element uptake, accumulation, and resorption in leaves of mangrove species with different mechanisms of salt regulation. Web Ecology, 15(1): 3-13.

Minh L. T. N., Orange D., Thai T. T., Garnier J., Anh L. L., Duc T. A., 2014. Hydrological regime of a tidal system in the Red River Delta, northern Vietnam. Paper presented at: Hydrology in a Changing World: Environmental and Human Dimensions; October, Montpellier, France: 451-456.

Minh N. V., Lien N. T. H., 2015. Effects of building dykes to physical, chemistry characteristics of land in coastal mudflat area Kim Son, Ninh Binh and vicinity. 
Paper presented at: The 6-th national scientific conference on ecology and biological resources; 21st Oct., Ha Noi. pp. 1520-1526. (in Vietnamese).

Nguyen H. Q., Pham T. T. N., Le T. V. H., Dao V. T., Quinn C., Carrie R., Stringer L., 2019. Spatial Planning Influences Mangrove Forest Development in Kim Son District of Ninh Binh Province. Geospatial information for a smarter life and environmental resilience Hanoi, Vietnam, FIG Working Week 2019: 1-19.

Nguyen H. T., Yoneda R., Ninomiya I., HArada K., Dao T. V., Sy T. M., Phan H. N., 2004. The effects of stand-age and inundation on carbon accumulation in mangrove plantation soil in Namdinh, Northern Vietnam. Tropics, 14(1): 21-37.

Norshazila S., Othman R., Jaswir I., Yumi Zuhanis H. H., 2017. Effect of abiotic stress on carotenoids accumulation in pumpkin plants under light and dark conditions. International Food Research Journal, 24: S387-S394.

Patel N. T., Pandey A. N., 2009. Salinity tolerance of Aegiceras corniculatum (L.) Blanco from Gujarat coasts of India. Anales de Biología, 31: 93-104.

Penna D. D., 1999. Carotenoid synthesis and function in plants: Insights from mutant studies in Arabidopsis. Pure and Applied Chemistry, 71(12): 2205-2212.

Rezazadeh A., Ghasemnezhad A., Barani M., Telmadarrehei T., 2012. Effect of Salinity on Phenolic Composition and Antioxidant Activity of Artichoke (Cynara scolymus L.) Leaves. Research Journal of Medicinal Plant, 6(3): 245-252.

Sasamoto H., Hayatsu M., Suzuki S., 2020. High Allelopathic Activity of Carotenoidaccumulating Callus of a Halophilic Mangrove Plant, Avicennia alba: Protoplast Co-culture Method with Digital Image Analysis. Journal of Plant Studies, 9(1): 1-12.

Scholander P. F., Hammel H. T., Hemmingsen E., Garey W., 1962. Salt balance in mangroves. Plant Physiol., 37(6): 722-729.

Strzalka K., Kostecka-Gugala A., Latowski D., 2003. Carotenoids and Environmental Stress in Plants: Significance of Carotenoid-Mediated Modulation of Membrane Physical Properties. Russian Journal of Plant Physiology, 50(2): 168-172.

Tan D. V., Thuy M. N., 2015. Antioxidant, Antibacterial and Alpha Amylase Inhibitory Activity of Different Fractions of Sonneratia apetala Bark. Academia Journal of Biology, 37 (1se): 54-60.

Tang V. T., 2006. The coastal wetlands of the Red river delta: Potentials, challenges and solution for sustainable development. In: Hong, P. N., ed. The role of mangrvoe and coral reef ecosystems in natural disaster mitigation and coastal life improvement. Agricultural Publishing House, Ha Noi, pp. 159-166.

Ulfat M , Athar H. R., Ashraf M., Akra, N. A., Jamil A., 2007. Appraisal of physiological and biochemical selection criteria for evaluation of salt tolerance in canola (Brassica napus L.). Pakistan Journal of Botany, 39(5): 1593-1608.

Wang L., Mu M., Li X., Lin P., Wang W., 2011. Differentiation between true mangroves and mangrove associates based on leaf traits and salt contents. Journal of Plant Ecology, 4(4): 292-301.

Wang Z., Yu D., Zheng C., Wang Y., Cai L., Guo J., Song W. and Ji L. 2019. Ecophysiological Analysis of Mangrove Seedlings Kandelia obovata Exposed to Natural Low Temperature at Near $30 \circ \mathrm{N}$. Journal of Marine Science and Engieering, 7(9): 292-303.

Wellburn A. R, 1994. The Spectral Determination of Chlorophylls a and $\mathrm{b}$, as well as Total Carotenoids, Using Various Solvents with Spectrophotometers of Different Resolution. Journal of Plant Physiology, 144(3): 307-313. 